\title{
Taphonomies of trajectory: the pre- and post-depositional movement of bones
}

\author{
Richard Madgwick $^{1}$ - Lee G. Broderick ${ }^{2}$
}

Published online: 1 September 2015

(C) Springer-Verlag Berlin Heidelberg 2015

Taphonomic analysis has great potential for reconstructing the pre- and post-depositional history of faunal assemblages and has come to the forefront of zooarchaeological research in recent years. The last decade has seen substantial advances in research on a wide range of taphonomic indices. New actualistic studies have considerably enhanced understanding of the impact of specific agents in defined environments (González et al. 2012; Andrews and Whybrow 2005; Armstrong and Avery 2014; Coumont 2009; Dirrigl and Perotti 2014; Klippel and Synstelien 2007; Krajcarz and Krajcarz 2014; Lloveras et al. 2014a, b; Marín-Arroyo and Margalida 2012; Montalvo et al. 2014; Rodríguez-Hidalgo et al. 2013; Rudzik et al. in press; Sala et al. 2014; Sanchis Serra et al. 2014). Controlled experiments have aided with approaches to identification and the differentiation of modifications (Blasco et al. 2008; Domínguez-Rodrigo et al. 2009; Domínguez-Solera and Domínguez-Rodrigo 2009; MarínMonfort et al. 2014). In addition, detailed archaeological investigations (Atici 2006; Conard et al. 2008; Enloe 2012; Gál 2008) and new approaches to modification recognition (Boschin and Crezzini 2012; Crezzini et al. 2014) and data analysis and usage (Bar-Oz and Munro 2004; Madgwick 2014; Madgwick and Mulville 2012, 2015a; Orton 2012) have provided greater detail on the way in which different processes inter-link. The field of taphonomic research has never been more vibrant. Although further progress is required and standardisation remains a major issue (Albarella

Richard Madgwick

MadgwickRD3@cardiff.ac.uk

1 School of History, Archaeology and Religion, Cardiff University, Cardiff, UK

2 Department of Archaeology, University of York, York, UK
2015; James and Thompson 2015), as processes and modifications become better understood, their interpretative potential in zooarchaeological research is increasingly wide-ranging. In spite of this, the systematic use of taphonomic data remains largely the realm of early prehistoric research, most commonly in Palaeolithic zooarchaeology.

Research on early prehistory has often focussed on identifying agents of accumulation and characterising the nature of consumption by defining deposits in terms of their modification and the bones they comprise. This reflects a continuing concern with demonstrating or discounting an assemblage's anthropogenic origins - a concern which contributed to the initial development of taphonomic studies in archaeology (Lartet 1860; Morlot 1861). Research on later assemblages, though less widespread, has tended to pay closer attention to processes of carcass division, dispersal and to a lesser extent refuse management. In spite of these different foci, certain themes are equally relevant to all archaeological assemblages, the pre- and post-depositional movement of bones being one example. Understanding the scale, intensity and character of bone movement on archaeological sites has wide-ranging ramifications for understanding site formation, humananimal relations and dietary practice. However, it is exceptionally rare that the movement of faunal remains is the principal focus of zooarchaeological research and it is largely undervalued in terms of its interpretative potential. Evidence for bone movement is all too often relegated to the status of a brief note and relatively rarely interrogated to the degree that it can be utilised to reconstruct social practices and biological processes. With the expansion of taphonomy as a sub-discipline, bone movement has become a greater focus, but research remains somewhat polarised, with the vast majority occurring in early prehistoric archaeology and little engagement between those studying different periods. Papers published in this special issue derive from a conference session 
that aimed to reconcile these paradigm-specific approaches by bringing together researchers from a broad spectrum of zooarchaeological studies.

The session took place at the 12th International Conference of Archaeozoology, San Rafael, Argentina, in September 2014. The 18 oral and poster presentations showcased research from seven continents ranging in date from the Pleistocene to the Post-Mediaeval period along with actualistic studies and discursive papers. The breadth of themes represented in the presentations demonstrated the dynamism of research on bone movement and in the wider discipline of taphonomy. Substantial cross-over was evident throughout the session, with researchers working on Late Pleistocene Tierra del Fuego tackling comparable issues (e.g. the interpretative validity of bone surface modifications) in a similar way to those working on Mediaeval assemblages from the UK. This facilitated just the sort of interaction that the session aimed to achieve, and the ICAZ Taphonomy Working Group meeting that followed was all the more vibrant as a result, with plans of ambitious global collaborations and cross-continent experimental studies discussed.

Whilst some of the diversity of the session has been lost in this special issue, the ten contributions that are published here demonstrate the potential of bone movement studies and the wideranging archaeological themes that detailed analysis can contribute to. Some of the papers show further refinements to models designed to help us identify the assemblage creator - a question which underpinned the initial adoption of taphonomic studies in zooarchaeology and which continues to drive much research. Working in the early twentieth century, Weigelt (1989) and Pei (1938) were the first to investigate the role of fluvial action in creating animal bone assemblages. Lopez et al.'s contribution to this volume builds on this legacy by explicitly recognising the complicated history of many assemblages. They investigate fluvial action as a secondary agent of assemblage creation in a marine landscape that was terrestrial at the time of initial deposition. Through meticulous analysis, they demonstrate that it is possible to identify several different accumulating agents - carnivore, rodent and fluvial and, importantly for the focus of this volume, to suggest what the implications of these taphonomic agents might be for the movement of bones.

If research into the effects of fluvial action on faunal assemblages has a long history in zooarchaeology then, as has already been intimated, the role of carnivores is even longerin fact extending to the beginnings of taphonomic research in the discipline. A major focus of research has always been on identifying the primary accumulating agent - in particular through the identification of gnawing marks or selective bone retrieval or destruction. Several of the papers presented in this issue seek to develop such research further by not only asking whether we can tell what the accumulating agent was but also how that agent might have moved bones to create the patterns we see archaeologically. Crezzini et al. present a detailed investigation into the distribution of bones through a single hyena den. This study makes a valuable contribution to the corpus of data on hyena accumulations and utilises fracture freshness, modification, fragmentation and \%MAU data integrated with fine-grained spatial analysis of bones and coprolites. In a more extensive study, Gutierrez et al. employed fieldwalking survey techniques to study the movement of bones across a variety of different ecozones in South America. Such modern analogue data is crucial for aiding our understanding of site formation, and its acquisition has a long history in taphonomic research (e.g. Dart 1956, 1959; Brain 1981). Gutierrez et al.'s study is particularly innovative in using wide-ranging taphonomic data to compare patterns across different habitat types. Ballejo et al. adopt a similar approach in investigating the movement of bones by carnivorous birds in South America. This study shows the value of both qualitative and quantitative data in observational research, for example, in combining detailed descriptions of modifications to specific anatomical landmarks with statistical correlations between elements represented in pellets and those missing from scavenged carcasses.

Both studies focus on an environment where native prey and predators co-exist with introduced species and modern farmers. In capturing the complex interplay of different agents, this makes them all the more important as zooarchaeological (rather than palaeontological) analogues. Importantly, such an extensive study as that of Gutierrez et al. reminds us that the movement of bones occurs across landscapes and is rarely limited to sites. Observational studies such as these have led some zooarchaeologists to define taphonomy as a means of filtering out some bias in the archaeological record (cf. Lyman 1994). Such a definition could be argued to be missing the point of taphonomic study. Its role is not merely to break down the barriers between the recovered assemblage and the original deposit but rather to be directly informative about past societies. For example, by comparing an archaeological assemblage with modern analogue data, it is possible to begin to interpret not just how that assemblage was created but how the archaeological site it came from was situated in its wider landscape-its role and connections.

Gutierrez et al. suggest that the understandings gleaned from their study could be further nuanced by experimental approaches to the movement of bones in natural environments. This is the principal focus of Filios' novel contribution to the special issue, which adopts a number of methods widely used in ecological research, including print traps and camera traps, to monitor the agents responsible for the dismemberment of carcasses and the consequent movement of bones in the Australian outback. The results of this study further highlight the issues of equifinality that plague zooarchaeological research and are sobering in demonstrating that the accurate reconstruction of multifaceted depositional histories is still beyond the capacity of current research methods in many 
instances. However, with detailed consideration of a wide range of indices, valuable insights can be gained into site formation processes in even the most complex of archaeological records, as demonstrated by Lopez et al.'s contribution. Oría et al. also show this in their analysis of assemblages from three different sites in Tierra del Fuego. Using a broad suite of taphonomic data, this study is one of relatively few that systematically uses lichen growth as a convincing indicator of stability.

In contrast to the aforementioned papers, Marchionni's study, also based in Argentina, is principally concerned with the post-depositional movement of bones (although consideration is also given to pre-depositional movement). In identifying rodents and tree roots as the primary agents of postdepositional movement, she is able to rule out redeposition as being a significant factor in accumulation history. Madgwick's paper further develops our abilities to understand the post-depositional movement of bones by providing a set of statistical tools for comparing the different impacts of modifying agents between sites. Doing so not only recognises the inherent heterogeneity of many assemblages but also moves us further towards disentangling equifinality and identifying unusual depositional histories. In focusing his research on midden deposits, Madgwick also highlights the human role in post-depositional as well as pre-depositional bone movement.

This role is brought into sharp relief by Rainsford and O'Connor. Focusing on the analysis of a large assemblage from the urban site of Hungate, York, in the UK, this paper (like Madgwick's) serves as a reminder of the value of taphonomic study to all environments and periods - it need not be confined to hunter-gatherer sites and carnivore mediation. Analysing the assemblage at a contextual level suggested several incidences of both the pre- and post-depositional movement of bones. Some of these were anthropogenic and some were likely the result of scavenging activities by carnivores and rodents - in all cases, however, the identification of the movement of bones has significantly added to our picture of life in and around the site throughout its use. Far from purely filtering bias, this is a clear statement of the powers of taphonomic studies for informing social interpretations.

Finally, and of particular relevance to the type of study presented by Rainsford and O'Connor, Albarella calls our attention to the terminology we use to describe different categories of bone movement on archaeological sites. Far from being an exercise in semantics, this important contribution should help to galvanise the discipline by facilitating more precise discourse. As Albarella points out in his paper, the furtherance of scientific research is dependent upon understanding and the clarity of meaning. His oral presentation inspired discussions at the Taphonomy Working Group meeting concerning the production of a comprehensive glossary for taphonomic research. Bone movement studies suffer from a diverse range of often ill-defined terms, and specifying the difference between 'residual' and 'redeposited' is thus of far more importance than someone outside of the discipline may realise.

In summary, an understanding of bone movement and the multitude of factors mediating it has long been recognised as key in disentangling the taphonomic events which impact upon faunal assemblages. However, the potential of bone movement studies for informing archaeological interpretation is yet to be fulfilled. The papers showcased in this special issue demonstrate the value of an increased focus on bone movement in zooarchaeology. It is our hope that this can act as a springboard for wider and more integrated research to extend the interpretative potential of bone movement studies and bring them to the forefront of taphonomic research, crosscutting environment- and period-specific paradigms.

This special issue is published in conjunction with the ICAZ Taphonomy Working Group, following the publication of proceedings of previous sessions and meetings in the International Journal of Osteoarchaeology in 2012 (volume 22, issue 5) and in Quaternary International in 2014 (volume 346). The editors would like to thank all presenters, discussants and authors for their valuable contributions to the session and the special issue along with the many reviewers who assisted in the delivery of this publication. We are also grateful to Professor Terry O'Connor for chairing several of the presentations and are greatly indebted to the organisers of ICAZ 2014 for all their efforts in delivering such a successful event and for making the session possible.

\section{References}

Albarella U (2015) Defining bone movement in archaeological stratigraphy: a plea for clarity. Archaeol Anthropol Sci doi:10.1007/s12520015-0269-9

Andrews P, Whybrow P (2005) Taphonomic observations on a camel skeleton in a desert environment in Abu Dhabi. Palaeontol Electron 8:1-17

Armstrong A, Avery G (2014) Taphonomy of Verreaux's Eagle (Aquila verreauxii) prey accumulations from the Cape Floral Region, South Africa: implications for archaeological interpretations. J Archaeol Sci 52:163-183

Atici AL (2006) Who let the dogs out? Bone destruction and its broader implications in interpreting the Bronze Age pastoral economies at Kaman-Kalehöyük. Anatol Archaeol Stud 15:121-132

Bar-Oz G, Munro ND (2004) Beyond cautionary tales: a multivariate taphonomic approach for resolving equifinality in zooarchaeological studies. J Taphonomy 2:201-220

Blasco R, Rosell J, Fernández Peris J, Cáceres I, María Vergeìs J (2008) A new element of trampling: an experimental application on the Level XII faunal record of Bolomor Cave (Valencia, Spain). J Archaeol Sci 35:1605-1618

Boschin F, Crezzini J (2012) Morphometrical analysis on cut marks using a 3D digital microscope. Int J Osteoarchaeol 22:549-562

Brain CK (1981) The hunters or the hunted? An introduction to African cave taphonomy. University of Chicago Press, Chicago 
Conard NJ, Walker SJ, Kandel AW (2008) How heating and cooling and wetting and drying can destroy dense faunal elements and lead to differential preservation. Palaeogeogr Palaeocl 266:236-245

Coumont M-P (2009) Proposition d'un référentiel taphonomique fossile de faunes issues d'avens-pièges. Ann Paleontol 95:1-20

Crezzini J, Boschin F, Boscato P, Wierer U (2014) Wild cats and cut marks: exploitation of Felis silvestris in the Mesolithic of Galgenbühel/Dos de la Forca (South Tyrol, Italy). Quatern Int 330: $52-60$

Dart RA (1956) The myth of the bone-accumulating hyena. Am Anthropol 58:40-62. doi:10.1525/aa.1956.58.1.02a00040

Dart RA (1959) Further light on Australopithecine humeral and femoral weapons. Am J Phys Anthropol 17:87-93. doi:10.1002/ajpa. 1330170202

Dirrigl F, Perotti L (2014) Taphonomic study of Japanese quail (Coturnix japonica) bone modification resulting from the burial and feeding behavior of the American burying beetle (Nicrophorus americanus). Int J Osteoarchaeol 24:272-278

Domínguez-Rodrigo M, de Juana S, Galán AB, Rodríguez M (2009) A new protocol to differentiate trampling marks from butchery cut marks. J Archaeol Sci 36:2643-2654

Domínguez-Solera SD, Domínguez-Rodrigo M (2009) A taphonomic study of bone modification and of tooth-mark patterns on long limb bone portions by squids. Int J Osteoarchaeol 19:345-363

Enloe JG (2012) Middle Palaeolithic cave taphonomy: discerning humans from hyenas at Arcy-sur-Cure, France. Int J Osteoarchaeol 22:591-602

Gál E (2008) Faunal and taphonomic analyses of a Late Pleistocene birdbone assemblage from a cave deposit in north-west Hungary. Geobios 41:79-90

González ME, Álvarez MC, Massigoge A, Gutiérrez MA (2012) Bone differential survivorship and ontogenetic development in guanaco (Lama guanicoe). Int J Osteoarchaeol 22:523-536

James EC, Thompson, JC (2015) On bad terms: Problems and solutions within zooarchaeological bone surface modification studies. Environ Archaeol 20:89-103

Klippel WA, Synstelien JA (2007) Rodents as taphonomic agents: bone gnawing by brown rats and gray squirrels. J Forensic Sci 52:765773

Krajcarz M, Krajcarz M (2014) The red fox (Vulpes vulpes) as an accumulator of bones in cave-like environments. Int J Osteoarchaeol 24: 459-475

Lartet ME (1860) On the coexistence of man with certain extinct quadrupeds, proved by fossil bones, from various Pleistocene deposits, bearing incisions made by sharp instruments. Q J Geol Soc 16:471479. doi:10.1144/GSL.JGS.1860.016.01-02.63

Lloveras L, Thomas R, Lourenço R, Caro J, Dias A (2014a) Understanding the taphonomic signature of Bonelli's Eagle (Aquila fasciata). J Archaeol Sci 49:455-471
Lloveras L, Nadal J, Moreno-García M, Thomas R, Anglada J, Baucells J, Martorell C, Vilasís D (2014b) The role of the Egyptian Vulture (Neophron percnopterus) as a bone accumulator in cliff rock shelters: an analysis of modern bone nest assemblages from Northeastern Iberia. J Archaeol Sci 44:76-90

Lyman RL (1994) Vertebrate taphonomy. Cambridge University Press, Cambridge

Madgwick R (2014) What makes bones shiny? Investigating trampling as a cause of bone abrasion. Archaeol Anthropol Sci 6:163-173

Madgwick R, Mulville J (2012) Investigating variation in the prevalence of weathering in faunal assemblages in the United Kingdom: a multivariate statistical approach. Int J Osteoarchaeol 22:509-522

Madgwick R, Mulville J (2015) Reconstructing depositional histories through bone taphonomy: extending the potential of faunal data. $\mathrm{J}$ Archaeol Sci 53:255-263

Marín-Arroyo A, Margalida A (2012) Distinguishing bearded vulture activities within archaeological contexts: identification guidelines. Int J Osteoarchaeol 22:563-576

Marín-Monfort MD, Pesquero MD, Fernández-Jalvo Y (2014) Compressive marks from gravel substrate on vertebrate remains: a preliminary experimental study. Quatern Int 330:118-125

Montalvo CI, Fernández FJ, Soledad Liébana M, Santillán M, Sarasola H (2014) Taphonomic analysis of rodent bone accumulations produced by the White-tailed Kite (Elanus leucurus, Accipitriformes) in Central Argentina. J Archaeol Sci 52:354-362

Morlot A (1861) General views on archaeology. Smithsonian Institution, Washington

Orton D (2012) Taphonomy and interpretation: an analytical framework for social zooarchaeology. Int J Osteoarchaeol 22:320-337

Pei WC (1938) Le rôle des Animaux et des Causes Naturelles dans la Cassure des Os. (Palaeontoligica Sinica, Series D, New series no. 7 (Whole series no. 118)). Geological Survey of China, Nanking

Rodríguez-Hidalgo A, Lloveras L, Moreno-García M, Saladié P, Canals A, Nadal J (2013) Feeding behaviour and taphonomic characterization of non-ingested rabbit remains produced by the Iberian lynx (Lynx pardinus). J Archaeol Sci 40:3031-3045

Rudzik SM, Fernández FJ, Carrera JD (In Press) Taphonomic analysis of micromammal remains from striped owl (Pseudoscops clamator) pellets in northeastern Buenos Aires province, Argentina: implications for archaeological sites formation. Int J Osteoarchaeol

Sala N, Arsuaga JL, Haynes G (2014) Taphonomic comparison of bone modifications caused by wild and captive wolves (Canis lupus). Quat Int 330:126-135

Sanchis Serra A, Real C, Morales JV, Pérez Ripoll M, Tormo C, Carrión Y, Pérez G, Ribera A, Bolufer J, Villaverde V (2014) Towards the identification of a new taphonomic agent: an analysis of bone accumulations obtained from modern Egyptian vulture (Neophron percnopterus) nests. Quatern Int 330:136-149

Weigelt J (1989) Recent vertebrate carcasses and their implications. University of Chicago Press, Chicago 